\title{
REDUÇÃO DO CUSTO DE PRODUÇÃO DE LAMINADOS A QUENTE NA ESPECIFICAÇÃO LNE 38 OU LNE 380 ATRAVÉS DA ALTERAÇÃO DE ROTA DE PRODUÇÃO DE REFINO NA ACIARIA*
}

\author{
Lidiane da Paixão Carvalho \\ Marcelo Porto Silva ${ }^{2}$ \\ Carlos Roberto Guinâncio Carvalho 3 \\ Janio André Tiburcio 4 \\ Carlaine Fonseca de Souza ${ }^{5}$
}

Resumo

Foi estudada uma forma de reduzir o custo de produção de aços que atendem a norma NBR 6656 LNE 38 (ou LNE 380) na Companhia Siderúrgica Nacional (CSN). Esses materiais são utilizados em peças de conformabilidade crítica principalmente para indústria automotiva. Na CSN, o Forno Panela tradicionalmente faz parte da rota obrigatória de fabricação desses materiais constituindo um "gargalo" de produção. Efetuou-se uma análise da composição química, então empregada para os aços e das propriedades mecânicas resultantes, e então se buscou uma nova composição que atendesse a norma e que permitisse outra rota de produção. Percebeu-se que uma redução no teor de manganês em relação ao normalmente utilizado propiciava uma melhor adequação à norma, além de permitir o uso de uma rota alternativa que maximizava a produção e permitia reduzir custos.

Palavras-chave: Aumento de produtividade; Redução de custos; Aços para Indústria Automobilística; Manganês.

\section{REDUCTION OF THE COST OF PRODUCTION OF HOT ROLLED IN SPECIFICATION LNE 38 OR LNE 380 THROUGH ALTERATION OF THE ROUTE OF PRODUCTION OF REFINING IN STEELMAKINGS}

\section{Abstract}

A way to reduce the cost of production of steel that meet the NBR 6656 LNE 38 (or LNE 380) in the Companhia Siderúrgica Nacional (CSN) was studied. These materials are used on parts with critical formability primarily for the automotive industry. In CSN, Ladle Furnace traditionally is part of the mandatory route of manufacturing these materials forming a "bottleneck" of production. It was conducted an analysis of the composition until then used for steels and of the resultant mechanical properties, and then sought a new composition within the standard that allowed another production route. It was noticed that a reduction in the content of manganese in relation to commonly used provided a better match to the standard, and allows the use of an alternative route maximizing production and minimizing costs.

Keywords: Increased productivity; Cost reduction; Steels for Automotive Industry; Manganese.

1 Engenheiro Metalurgista, Engenheiro de Desenvolvimento, Gerência de Produtos Laminados, Companhia Siderúrgica Nacional, Volta Redonda, RJ, Brasil.

2 Engenheiro Metalurgista, Coordenador, Gerência de Produtos Laminados, Companhia Siderúrgica Nacional, Volta Redonda, RJ, Brasil.

3 Engenheiro Metalurgista, MSc., Coordenador, Gerência de Desenvolvimento de Produtos, Companhia Siderúrgica Nacional, Volta Redonda, RJ, Brasil.

4 Técnico Metalúrgico, Técnico de PCP, Gerência de Planejamento da Produção, Companhia Siderúrgica Nacional, Volta Redonda, RJ, Brasil.

5 Engenheiro Metalurgista, Gerente, Gerência de Produtos Laminados, Companhia Siderúrgica Nacional, Volta Redonda, RJ, Brasil.

\footnotetext{
* Contribuição técnica ao $51^{\circ}$ Seminário de Laminação - Processos e Produtos Laminados e
} Revestidos, 28 a 31 de outubro de 2014, Foz do Iguaçu, PR, Brasil. 


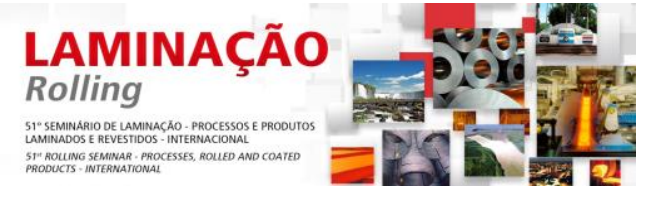

O manganês também é adicionado para contribuir no aumento da resistência mecânica dos aços através do mecanismo de endurecimento por solução sólida. A adição de solutos ao aço provoca distorções na rede cristalina, o que dificulta o movimento das discordâncias, gerando o endurecimento do material. A influência do manganês no aumento do limite de escoamento por solução sólida em aços baixocarbono em geral é da ordem de $3,2 \mathrm{MPa}$ a cada $0,1 \%$, para as faixas percentuais comercialmente utilizadas.

Dessa forma, o estudo de caso dos aços que atendem a norma NBR 6656 LNE 38 (ou LNE 380) produzidos pela CSN permitiu avaliar a influência da composição química (em especial do $\mathrm{Mn}$ ) nas propriedades finais desse material e a possibilidade de tomada de ação para aumento da produtividade e redução de custos desse produto. Na CSN, o processo de refino secundário desses aços tem tradicionalmente o Forno Panela como rota obrigatória, todavia isso constitui um "gargalo" de produção. Almeja-se encontrar uma rota alternativa que torne sua produção mais ágil e menos complexa, e que garanta os requisitos requeridos por norma e aplicações finais nos clientes.

\section{MATERIAIS E MÉTODOS}

O estudo concentrou-se nos aços que obedecem a norma NBR 6656 LNE 38 (ou LNE 380), os quais atendem, dentre outros específicos, aos requisitos gerais apresentados nas tabelas 1 e 2 .

Tabela 1. Composição química da especificacão

\begin{tabular}{lccccccc}
\hline $\begin{array}{l}\text { Grau da } \\
\text { norma }\end{array}$ & $\begin{array}{c}\text { C máx } \\
\%\end{array}$ & $\begin{array}{c}\text { Mn máx } \\
\%\end{array}$ & Si máx \% & P máx \% & S Max \% & $\begin{array}{c}\text { Nb Max } \\
\%\end{array}$ & Ti Max \% \\
\hline LNE380 & 0,12 & 1,10 & 0,35 & 0,025 & 0,015 & 0,12 & 0,2 \\
\hline
\end{tabular}

Tabela 2. Propriedades mecânicas da especificação

\begin{tabular}{llll}
\hline Grau da norma & LE ( Mpa) & LR ( Mpa $)$ & Al \% \\
\hline LNE 38/380 & $380 / 530$ & $460 / 600$ & 23 mín \\
\hline
\end{tabular}

São dois os principais produtos atendidos por essa Norma: os com espessura menores $(\leq 6,30 \mathrm{~mm})$, que têm processo termomecânico mais severo com maior deformação a quente e, consequentemente, gerando grãos ferríticos mais refinados; e aqueles com espessuras maiores $(>6,30 \mathrm{~mm}$ ) que tendem a apresentar valores mais baixos de limite de escoamento devido ao menor refinamento da microestrutura. Nessa etapa do projeto optou-se por focar a atenção unicamente nos materiais mais finos.

Efetuou-se então, testes industriais reduzindo o teor de manganês, que possibilitasse a alteração da rota de refino secundário para a Estação de Borbulhamento e definindo condições mais adequadas do processamento termomecânico.

Foram testadas 4000 toneladas de material com a nova composição química e os resultados das propriedades mecânicas foram comparados com os anteriores e com a norma para validá-los na especificação de interesse. 


\section{RESULTADOS E DISCUSSÃO}

A forma original de produção resultava em um aço com alto teor de manganês. Dessa maneira, entregava-se ao cliente um material com limites de escoamento aproximadamente $70 \mathrm{MPa}$ superiores ao mínimo exigido por Norma conforme (figura 1).

Os valores de limite de escoamento após alteração está representado na (figura 2). A comparação dos valores anteriores de limite de escoamento com os atuais mostram a efetividade da ação tomada no processo de fabricação desse material sem perdas significativas de propriedade mecânica.

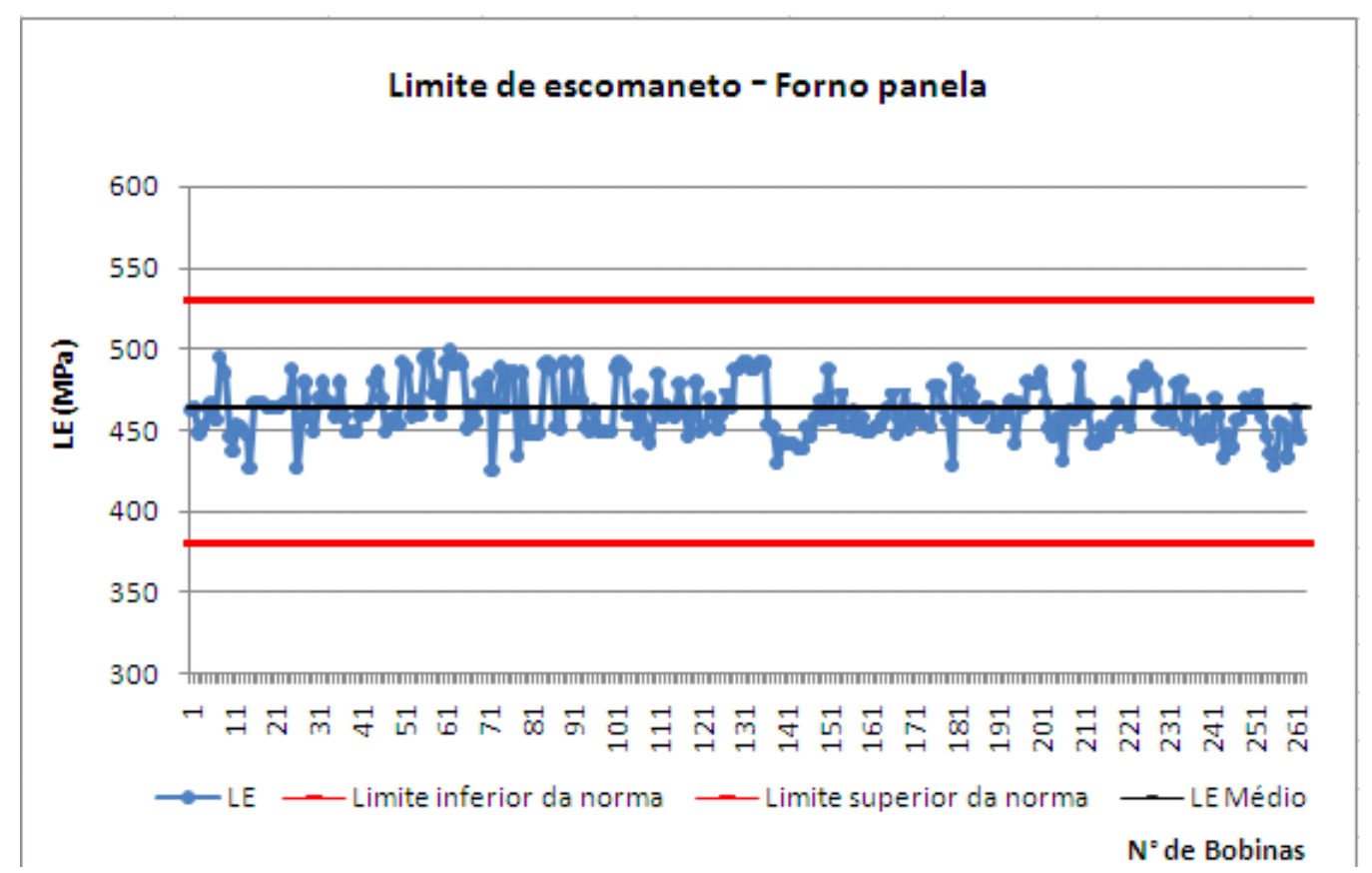

Figura 1. Gráficos de controle do limite de escoamento - Grau processado no Forno Panela

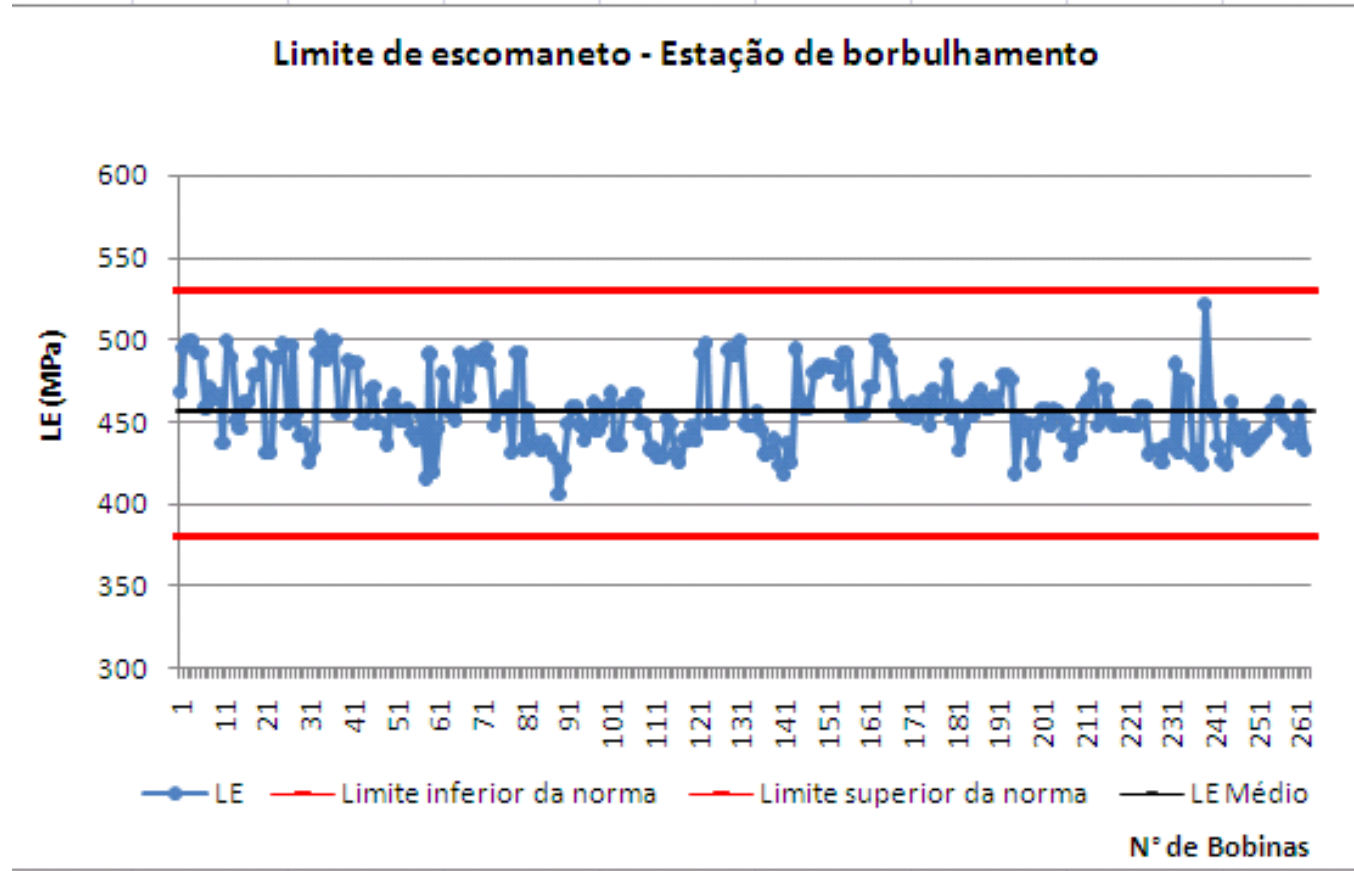

Figura 2. Gráficos de controle do limite de escoamento das bobinas de teste - Grau processado na estação de borbulhamento.

* Contribuição técnica ao $51^{\circ}$ Seminário de Laminação - Processos e Produtos Laminados e Revestidos, 28 a 31 de outubro de 2014, Foz do Iguaçu, PR, Brasil. 


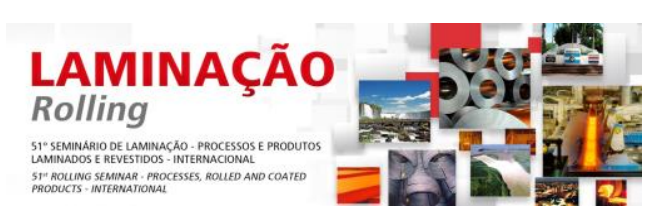

Nos testes realizados houve um ganho de tempo de processo na aciaria e nenhuma alteração característica de processo no laminador de tiras a quente que gerasse perda de produtividade. A Estação de Borbulhamento, equipamento com disponibilidade de produção e de menor custo de operação, tornou-se a nova rota para estes materiais, sem prejuízo às características desejadas.

Além disso, desde o início do projeto, não foi identificado qualquer desvio interno de qualidade ou reclamação de cliente que pudesse estar associado à alteração realizada.

A alteração para os materiais finos da especificação LNE38 / 380 contribuiu para redução do custo do produto sem detrimento das propriedades mecânicas de atendimento.

\section{CONCLUSÃO}

A redução do teor de manganês foi suficiente para estabelecer uma rota alternativa de produção do aço que atende a Norma NBR6656 LNE38 ou 380, mantendo as características químicas e mecânicas dentro da especificação.

O desenvolvimento deste trabalho permitiu disponibilizar o Forno-Panela para a produção de aços de composição química mais complexa, de maior criticidade e com maior valor agregado. Também possibilitou 0 aumento de volume disponibilizado para a produção da especificação LNE38 ou 380.

A implantação desse projeto permitiu redução no tempo de produção e custo do aço, maximizando o resultado financeiro da empresa e tornando-a mais competitiva no mercado.

\section{Agradecimentos}

Aos funcionários da CSN, que de forma direta ou indireta, contribuíram para a realização deste trabalho.

\section{BIBLIOGRAFIA}

1 Metals Handbook, vol 14, Forming and Forging, 9ª Ed., Ohio: ASTM Int., 1988.

2 Souza CF, Neto TMA, Silva MP, Aredes LN. Adequação do teor de manganês nos aços produzidos pela Companhia Siderúrgica Nacional. Associação Brasileira de Metalurgia, Materiais e Mineração. Anais do 49 Seminário de Laminação, Processos e Produtos Laminados e Revestidos; 2012; Vila Velha, Brazil.

* Contribuição técnica ao $51^{\circ}$ Seminário de Laminação - Processos e Produtos Laminados e Revestidos, 28 a 31 de outubro de 2014, Foz do Iguaçu, PR, Brasil. 